\title{
Impact of His bundle pacing versus right ventricle pacing on right ventricular performance in patients undergoing permanent pacemaker implantation
}

Domenico Grieco ${ }^{1}$, Edoardo Bressi ${ }^{2}$, Karol Curila ${ }^{3}$, Santosh Padala ${ }^{4}$, Kamil Sedlacek ${ }^{5}$, Jordana Kron $^{6}$, Elisa Fedele ${ }^{2}$, Ermenegildo de Ruvo ${ }^{7}$, Kenneth Ellenbogen ${ }^{8}$, Leonardo Calò $^{2}$, Oana Ionita ${ }^{3}$, Sara Giannuzzi ${ }^{2}$, Alessandro Fagagnini ${ }^{2}$, Jessica Formichetti ${ }^{2}$, Luca Sangiovanni ${ }^{2}$, Monia Minati ${ }^{9}$, and Germana Panattoni ${ }^{2}$

${ }^{1}$ Policlinico Casilino of Rome

${ }^{2}$ Policlinico Casilino

${ }^{3}$, Charles University and University Hospital Kralovske Vinohrady

${ }^{4}$ Virginia Commonwealth University, Medical College of Virginia hospitals

${ }^{5}$ University Hospital Hradec Kralove

${ }^{6}$ Virginia commonwealth University

${ }^{7}$ Policlinico Casilino, ASL RM/B

${ }^{8}$ Virginia Commonwealth University

${ }^{9}$ Policlinico Casilino, ASL Roma B

September 8, 2020

\begin{abstract}
Introduction. His Bundle pacing (HBP) is an emerging pacing technique that reproduces a more physiological ventricular synchronization than right ventricle pacing (RVP). However, its effects on the right ventricle (RV) performance are still unknown. Methods. In this observational study, we enrolled 84 patients (mean age $75.1 \pm 7.9$ years, $64 \%$ male) with indication for pacemaker implantation to compare the effects of HBP versus RVP on RV performance. 42 patients (50\%) underwent successful HBP and 42 patients (50\%) apical RVP. Patients were evaluated both at baseline and after six months by transthoracic echocardiogram. Results. At six months follow up, we found a significant improvement in RV-GLS (baseline: HBP $-17.2 \pm 4.7$ vs. RVP $-16.1 \pm 3.7$ to 6 -months: HBP $-19.5 \pm 4.2$ vs. RVP $-13.6 \pm 2.9, \mathrm{p}=<0.0001$ ) and RV-FAC (baseline: HBP $33.8 \pm 3.9 \%$ vs. RVP $33.3 \pm 5.3 \%$ to 6-months: HBP $36.2 \pm 3.7 \%$ vs. RVP $30.9 \pm 5.1 \%, \mathrm{p}=<0.0001)$ with HBP whereas RVP was associated with a significant decline in both parameters. Moreover, RVP was associated with a significant worsening of TAPSE (baseline: HBP $20.2 \pm 4.1 \mathrm{~mm}$ vs. RVP $21.2 \pm 4.3 \mathrm{~mm}$ to 6-months: HBP $20.3 \pm 3.8 \mathrm{~mm}$ vs. RVP $18.5 \pm 3.5 \mathrm{~mm}, \mathrm{p}=0.014$ ) and tricuspid $\mathrm{S}$ wave velocity (baseline: HBP $11.2 \pm 2.9 \mathrm{~cm} / \mathrm{sec}$ vs. RVP $11.8 \pm 2.3 \mathrm{~cm} / \mathrm{sec}$ to 6 -months: HBP $11.3 \pm 2.2 \mathrm{~cm} / \mathrm{sec}$ vs. RVP $10.3 \pm 1.9 \mathrm{~mm}, \mathrm{p}<0.0001)$ compared to HBP. Conversely from RVP, HBP significantly improved PASP (baseline: HBP $36.7 \pm 7.3 \mathrm{mmHg}$ vs. RVP $34.6 \pm 6.1 \mathrm{mmHg}$ to 6 -months: HBP $32.4 \pm 5.9 \mathrm{mmHg}$ vs. RVP $38.7 \pm 5.6 \mathrm{mmHg}, \mathrm{p}<0.0001)$ and tricuspid regurgitation $(\mathrm{p}=0.005)$ at six-months. Conclusions. HBP ensues a beneficial and protective impact on RV performance compared with RVP.
\end{abstract}

\section{Hosted file}

08092020Mico - final version.pdf available at https://authorea.com/users/357276/articles/ 479889-impact-of-his-bundle-pacing-versus-right-ventricle-pacing-on-right-ventricularperformance-in-patients-undergoing-permanent-pacemaker-implantation 